\title{
Nomadic Behavior of an Old and Formerly Territorial Eastern Coyote, Canis latrans*
}

\author{
JONATHAN G. WAY ${ }^{1}$ and BRAD C. TIMM ${ }^{2}$ \\ ${ }^{1}$ Eastern Coyote Research, 89 Ebenezer Road, Osterville, Massachusetts 02655 USA \\ ${ }^{2}$ Department of Natural Resources Conservation, Holdsworth Natural Resources Center, University of Massachusetts, Amherst, \\ Massachusetts 01003 USA; e-mail: bradtimm@gmail.com
}

Way, Jonathan G., and Brad C. Timm. 2008. Nomadic behavior of an old and formerly territorial eastern Coyote, Canis latrans. Canadian Field-Naturalist 122(4): 316-322.

We document the fate of a female Eastern Coyote on Cape Cod, Massachusetts that was a breeding resident of a $\sim 30 \mathrm{~km}^{2}$ territory for at least six years $(1998$ - 2004) and then became nomadic. Her behavior dramatically changed in January 2005, when she was located on six occasions sleeping under sheds and/or decks in highly residential neighborhoods at the southeastern edge of her range. On 11 March 2005 she localized in a small area $\left(95 \%\right.$ MCP range $\left.=5.85 \mathrm{~km}^{2}\right)$ at the northeastern edge of her old territory, where she remained until 1 March 2006. After briefly associating with other Coyotes (late-February 2006), her movement patterns changed again. She used a much larger area $\left(\sim 200 \mathrm{~km}^{2}\right)$ until she was shot dead in February 2007 . Tracking data indicated that she lived in localized areas during this nomadic period, possibly to avoid resident Coyote packs.

Key Words: Eastern Coyote, Canis latrans, nomadic movements, post-reproductive, suburban, transient, urbanized, Cape Cod, Massachusetts.

Eastern Coyotes (Canis latrans), like Wolves (Canis lupus), typically live in territorial social groups consisting of a breeding pair, their full-grown offspring (termed "beta" or "pack-associates"; usually one or two year-old individuals), and pups of the year (Gese et al. 1996; Mech et al. 1998; Patterson and Messier 2001; Way et al. 2002a; Mech and Boitani 2003b; Way 2003). In addition, lone individuals (termed "dispersers", "nomads", "transients", or "floaters") travel among resident packs and live in larger areas, in some instances traveling hundreds of miles from their birthplace (Mech and Boitani 2003b; Parker 1995; Way 2007). These nomadic individuals (both Eastern Coyotes and Wolves) are typically young (i.e., one-to twoyear-old) animals that, in many cases, eventually establish territories as adults and cease their nomadic movements (Gese and Mech 1991; Harrison 1992; Mech et al. 1998; Mech and Boitani 2003a,b).

Little information currently exists on the behavior and movements of older canids (> 8-10 yr old) in part because they are rarely reported in the wild (Parker 1995: 85; Mech and Boitani 2003b; although see Dumond and Villard 2000 and Way and Strauss 2004). Mech and Boitani (2003a) noted that female Wolves generally reproduce until they die, but there is the possibility that they may become senescent if they survive long enough (i.e., 10 - 15 years). Detailed observations of individual canids over long periods of time are rarely reported because studies are typically shortterm in duration, the animal dies at a younger age, and/or the animal's radio-transmitter fails. However, D. Mech followed a female Wolf (\#2473) in Minnesota from her early nomadic phase as a lone Wolf, through several years as a territorial breeder, and then through her loss of that status (subsequently becoming nomadic again) following the death of her mate when a new male integrated into the pack and paired with her daughter (F. Harrington, persersonal communication). These anecdotes provide a personal and intimate account of canid behavior that is rarely reported in more comprehensive studies (e.g., Harrison 1992; Gese et al. 1996; Way et al. 2002a, 2004).

In this paper, we report results obtained from over eight years of radio-telemetry data collection on a female Coyote on Cape Cod, Massachusetts was a breeding resident for at least six of these years and subsequently became a nomad or floater.

\section{Methods}

Study Area

The majority of the field work in this study was conducted in the urbanized town of Barnstable $\left(155 \mathrm{~km}^{2}\right)$, Cape Cod, Massachusetts, where human population density was 308 people $/ \mathrm{km}^{2}$ and housing density was $161 / \mathrm{km}^{2}$. The entire Barnstable County (i.e., Cape Cod, $1024 \mathrm{~km}^{2}$ ), which includes the areas that the Coyote reported here (code-named "Casper", ID \#9804) used when nomadic (Figures 1 and 2), averaged 217 peo$\mathrm{ple} / \mathrm{km}^{2}$ and 144 houses $/ \mathrm{km}^{2}$ (U. S. Census Bureau 2000 estimates). Cape Cod is a residential area interspersed with numerous small (5-10 ha) and several large (100 - 500 ha) conservation areas. Most of the neighborhoods are not fenced, allowing Coyotes to travel through these areas to access various portions of fragmented home ranges (Way et al. 2004).

*See Addenda following literature cited. 

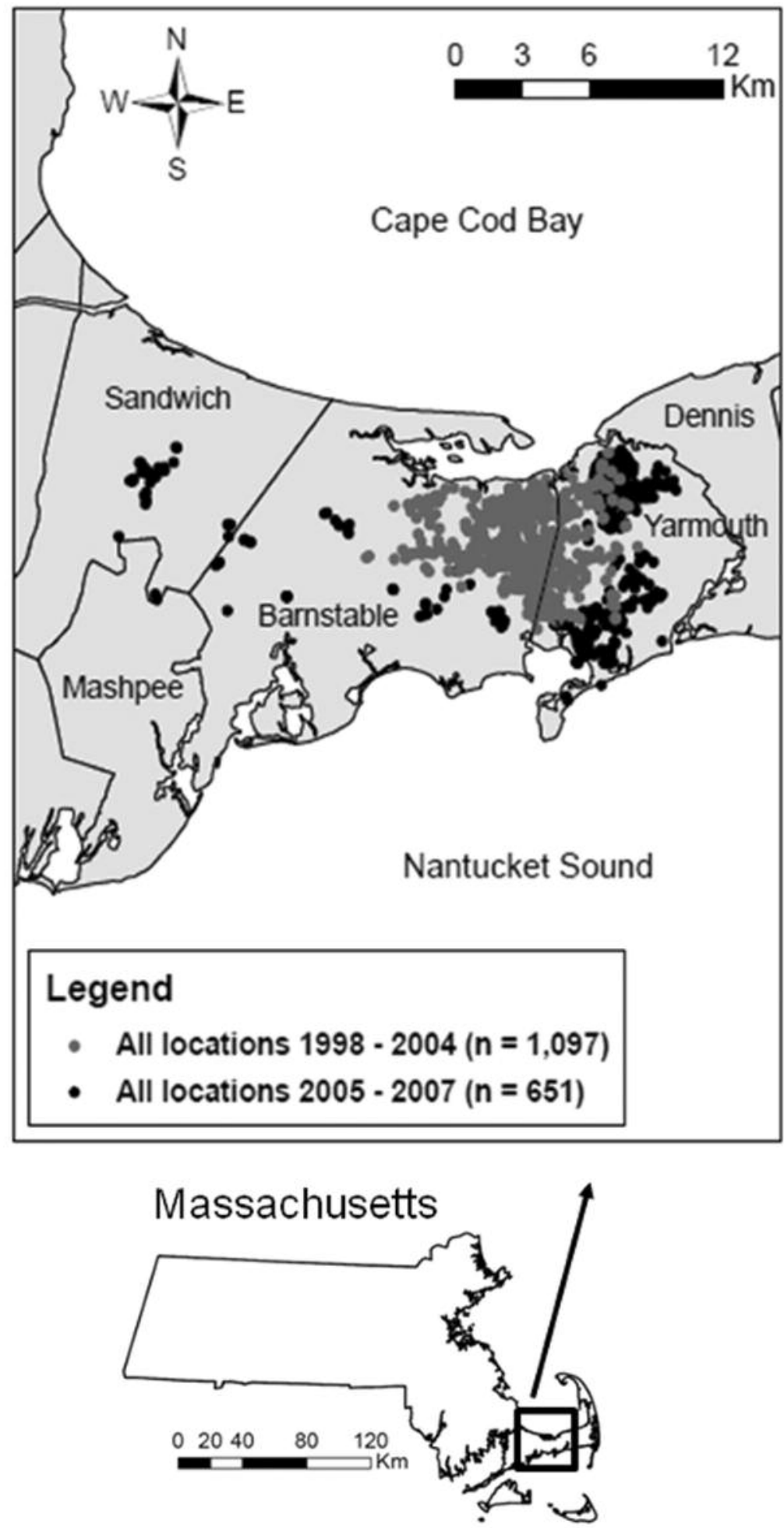

FIGURE 1. Study area focusing around the town of Barnstable on Cape Cod, Massachusetts, and all telemetry locations for Coyote \#9804 (“Casper”) from 1998 through 2007. 
TABLE 1. Number of telemetry locations and $95 \%$ and $100 \%$ Minimum Convex Polygon (MCP) home range estimates (in $\mathrm{km}^{2}$ ) for Eastern Coyote \#9804 for each year of telemetry from 1999 through 2007. No locations were obtained during 2003 because her collar was non-functioning.

\begin{tabular}{lccccc}
\hline \hline & \multicolumn{5}{c}{ Location attempts } \\
\cline { 2 - 5 } Year & Total & $\mathrm{S}^{1}$ & $\left(\% \mathrm{~S}^{1}\right)$ & $95 \% \mathrm{MCP}$ & $100 \% \mathrm{MCP}$ \\
\hline 1998 & 28 & 25 & 90 & 27.64 & 29.53 \\
1999 & 410 & 401 & 98 & 32.79 & 51.06 \\
2000 & 183 & 183 & 100 & 33.36 & 41.43 \\
2001 & 260 & 83 & 88 & 31.04 & 41.47 \\
2002 & 94 & 0 & $\mathrm{n} / \mathrm{a}$ & $\mathrm{n} / \mathrm{a}$ & $\mathrm{n} / \mathrm{a}$ \\
2003 & 0 & 145 & 98 & 17.05 & 20.70 \\
2004 & 145 & 202 & 89 & 10.60 & 15.04 \\
2005 & 207 & 443 & 27 & 190.12 & 196.57 \\
2006 & 495 & 3 & 95 & & $205.84^{2}$ \\
2007 & 11 & 1745 & & \\
Total & 1833 & &
\end{tabular}

${ }^{1} \mathrm{~S}=$ successful radio-location

${ }^{2}$ Includes 2006/2007 data (446 locations)

TABle 2. Percent overlap in 95\% Minimum Convex Polygon home ranges between years for Coyote \#9804. We captured her at the end of 1998 (hence low overlap with 1999-2004) and 2003 is not included because the Coyote carried a non-functioning radio-collar.

\begin{tabular}{rllllrrrr}
\hline \hline & 1998 & 1999 & 2000 & 2001 & 2002 & 2004 & 2005 & 2006 \\
\hline 1998 & - & 72.3 & 62.7 & 63.4 & 47.1 & 44.5 & 25.5 & 99.8 \\
1999 & 61.0 & - & 86.2 & 82.7 & 68.5 & 51.9 & 6.5 & 100.0 \\
2000 & 52.0 & 84.7 & - & 80.2 & 73.9 & 51.0 & 2.0 & 100.0 \\
2001 & 56.4 & 87.3 & 86.2 & - & 76.5 & 100.0 & 0.5 & 100.0 \\
2002 & 50.5 & 87.2 & 95.8 & 92.2 & - & 61.0 & 0.0 & 100.0 \\
2004 & 72.1 & 99.8 & 99.8 & 95.6 & 92.2 & - & 0.0 & 100.0 \\
2005 & 66.4 & 20.2 & 6.2 & 1.6 & 0.0 & 0.0 & - & 5.5 \\
2006 & 14.5 & 17.2 & 17.5 & 16.3 & 13.5 & 9.0 & 5.5 & - \\
\hline \hline
\end{tabular}

\section{Radio-telemetry}

The Coyote was originally captured in a box trap (Way et al. 2002b) in November 1998 in the town of Barnstable. She was a large, robust 2.5 or 3.5 year-old female who weighed $23.2 \mathrm{~kg}$ and was 1.48 meters long (tip of nose to tail-tip) upon initial capture. She was subsequently captured three more times during her lifetime and ranged in weight from 19.6 to $25.1 \mathrm{~kg}$ (see Way et al. 2001, 2002a; Way and Proietto 2005; and Way $\left.2007^{*}\right)$. Following capture, she was fitted with a radio-collar or it was replaced (MOD 335 and MOD 400 collars; Telonics Inc., Mesa, Arizona, USA) for monitoring purposes. Radio-telemetry protocols are fully described in Way et al. (2002a) and Way et al. (2004). Portable receivers (Custom Electronics, Urbana, Illinois, USA) and hand-held 3-element Yagi antennas were used to radio-track both on foot and from a vehicle. The abundance of roads restricted our activities to cars, as Coyotes did not react to them as much as to people (e.g., by running away; J. Way, unpublished data). Occasionally we approached the Coyote as close as possible on foot without disturbing her. Using a vehicle, we homed in on the animal's signal until its location was pinpointed by using the loudest-signal method (Way et al. 2004). We used binoculars, spotting scopes, and video-cameras during daytime observations, and city street lights, night vision scopes, binoculars, and headlights during nighttime observations (Way et al. 2002a, 2004).

To estimate home ranges (1998-2006/2007), we used Home Range Tools for ArcGIS extension using ArcGIS Version 9.2 (Rodgers et al. 2007). Home ranges/territories were calculated using the 100\% and 95\% Minimum Convex Polygon (MCP) methods. We conducted a Chi-square $\left(\chi^{2}\right)$ test of homogeneity to examine the proportion of successful vs. unsuccessful radiolocations compared between 1998-2004 and 20052007.

\section{Observations}

Territorial phase (1998-2004)

The studied individual was the breeding female of the "Cummaquid pack" from 1998 to 2004. During that time, she used a consistent territory of approximately $30 \mathrm{~km}^{2}$ (95\% MCP; Tables 1 and 2, Figures 1 and 2), led a pack of three to four adults (winter observations, 
after pup dispersal), and gave birth to an average of five pups in early April (Way et al. 2001) of each year. We obtained 1097 telemetry-locations on the Coyote during this time (Table 1), excluding April 2002 March 2004 when she wore a non-functioning radiocollar. However, based on Coyote observations in the area, it appears that she whelped a litter during summers 2002 and 2003 as she localized in April 2002 prior to her second collar's failure. In March 2004 she was observed traveling in a pack of four full-sized individuals, with one or two of those animals likely being her pups from 2003 (Gese et al. 1996; Way et al. 2002a).

\section{Nomadic phase \#1 (January 2005 - March 2006)}

Her behavior changed dramatically in January 2005 when, during a two-week period when $90 \mathrm{~cm}$ of snow fell, she was located on six occasions sleeping under sheds and/or decks (Figure 3) in highly residential neighborhoods at the southeastern edge of her range (Figures 1 and 2). During this period JGW observed a superficial wound on her left flank (which appeared to be Coyote-inflicted) though she otherwise appeared to be healthy. After six years of tracking her, JGW had the impression that something happened (i.e., a confrontation with other Coyotes) that may have caused this change in her behavior. Also, a few days before she was documented off-territory, JGW observed two other Coyotes vigorously scent-marking and groundscratching sandpits in the southwestern portion of her former range.

The Coyote was nomadic for approximately 1.5 months until 11 March 2005, when she localized in a small area $\left(95 \%\right.$ MCP range $=5.85 \mathrm{~km}^{2}$ and $100 \%$ MCP range $=7.89 \mathrm{~km}^{2}$; Figures 1 and 2) in the northeastern portion of the study area until 1 March 2006. While she was in that small area, we obtained 283 locations on her, visually observing her on 13 times: (1) alone during six occasions, (2) with another Coyote during four occasions (likely the same individual on all four occasions based on physical appearance) over a 9-month time-span (April 2005 - January 2006), and (3) three times in a one-week stretch during lateFebruary 2006 with her former mate (wearing a nonfunctioning collar from 2001 to 2006; see Way 2007*) and, on the last of those observations, also with a third, very large gray individual. Shortly after this observation (1 March 2006), she became nomadic and left the northeastern portion of her range for the southeastern region (i.e., the area where she was first located when leaving her territory in January 2005). During her tenure in the northeastern portion of her old range (i.e., 2005-2006; Figure 1) she did not give birth (or localize) despite being located with other Coyotes during $7 / 13(\sim 54 \%)$ of our direct observations of her.

\section{Nomadic phase \#2 (March 2006 - February 2007)}

It was more difficult to locate the Coyote during 2005-2006 (after she abandoned her territory) than

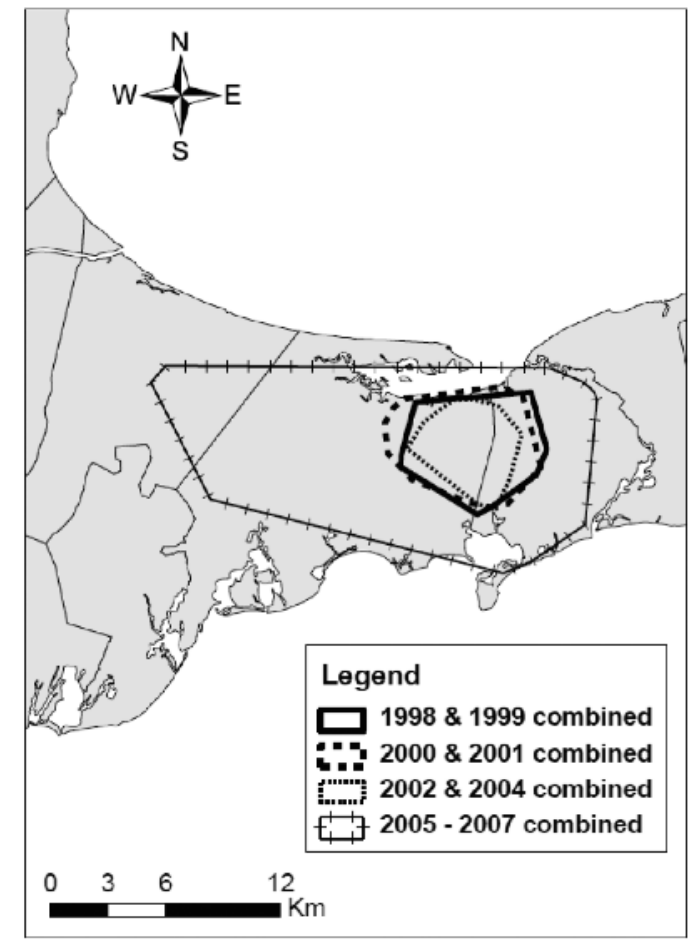

FIGURE 2. Eastern Coyote \#9804's 95\% minimum convex polygon home ranges on Cape Cod, Massachusetts grouped by 2 -year combinations. No locations were taken in 2003 because her collar was non-functioning.

when she held a territory (i.e., 1998-2004; $\chi^{2}=47.6$, df $=1, P<0.0001$; Table 1$)$. Because we were unsuccessful in obtaining a location for her during a large number of attempts in 2006 (Table 1), her home range for this period should be considered a minimum estimate, as she undoubtedly used areas outside of the 2006 polygon (Table 1, Figure 2 ). While it intuitively might be expected that we would have less success $(\sim$ five times more unsuccessful finds [11\% vs. $2 \%]$ in $2006 / 2007$ vs. 1998-2004) locating her in 2006/07 due to her larger range compared to previous years (i.e., approximately five to ten times larger during 20062007 compared to 1998-2004), we always managed to locate her the next day after not finding her in 1998 (unsuccessful locations were likely because of researcher inexperience), and in 2002 she had a weak battery which ultimately died, making her difficult to find. However, at the end of 2006 and into 2007 she was often not located for two to three months at a time and we believe she was off our study area during those unsuccessful finds (Table 1).

The Coyote's range during 2006 had minimal overlap with her former range (i.e., 1998 - 2004), suggesting that she avoided her original territory (Table 
2). Between March 2006 and February 2007 we observed the Coyote 28 times and she was alone every time. An additional two sightings involved Coyotes sighted in close proximity $(<200 \mathrm{~m})$ to her though not with her. The day after both of these observations, the Coyote moved a considerable distance away from the immediate area including a $5.7 \mathrm{~km}$ straight-line movement within a 24-hour time frame from the southeastern to the northeastern portion of her range (Figure 1) in late-March 2006. We do not think that humans influenced these movements as we often observed her during her territorial phase (i.e., 1998 - 2004; > 50 observations) and she never displayed dramatic movements following a sighting even when she was disturbed (i.e., by headlights).

\section{General nomadic phase observations}

Analyses of movements post-January 2005 (Figure 1) indicate that the Coyote used clustered areas, generally spending more time in areas where other radiocollared Coyotes were not located (J. Way, unpublished data). Interestingly, we observed Red Foxes (Vulpes vulpes) in close proximity (about 100 to $200 \mathrm{~m}$ ) to the Coyote during 15 to 20 observations of her during 2006 but never saw foxes near her from 1998 to 2004 when she was part of the Cummaquid pack. Also, many of the observations from $2005-2006$ were in highly residential areas (including Hyannis, 556 peo$\mathrm{ple} / \mathrm{km}^{2}$, the most urban part of Cape Cod), where radio-collared territorial resident Coyotes spent little time (J. Way, unpublished data).

\section{Discussion}

This study documents the movements of a postterritorial canid. This animal was a survivor, living a long full life in an urbanized area, but exhibiting behavior typical of a wild Coyote by avoiding people, living in a pack, and having a large territory (Way, $2007^{*}$ ). The extensive duration of our study on this particular Coyote (i.e., 1998-2007) enabled us to compare movement patterns between years when she was reproductive to years when she was not. Our results indicate that the Coyote maintained a relatively consistent territory during years when she whelped pups (1998 - 2004; Table 2, Figure 2) and then, during the final two years of her life (early-2005 to early-2007), her movement patterns changed dramatically. After becoming post-territorial in 2006/2007, she used an area of $\sim 200 \mathrm{~km}^{2}$, which was considerably larger than her annual territories from 1998-2004 (Table 2; Figure 2) but small when compared to long-distance movements observed in transient/nomad Wolves (Gese and Mech 1991; Mech and Boitani 2003a) and Coyotes (Way 2007). Such observations suggest that the classification of Coyotes as either residents (breeders/alphas, associates/betas/helpers, and juveniles/pups) or transients/nomads (Andelt 1985; Person and Hirth 1991; Patterson and Messier 2001; Way et al. 2002a) may be too simplistic. For example, Crabtree and Sheldon
(1999) described a subclass of solitary Coyotes, called "former alphas", who maintain a degree of site fidelity within a general area. It seems then that there may be (at least) two classes of nomadic/transient Coyotes: (1) "dispersers", who leave their natal range and settle in new, often distant areas (as is most frequently reported in the literature - e.g., Gese and Mech 1991; Way 2007); and (2) "floaters", who are animals that remain in a relatively localized area (though larger than an average pack's territory) moving in and out of existing pack mosaics, presumably looking for a territorial vacancy. Scenario number two is similar to many species of birds, such as Black-capped Chickadees (Parus atricapillus), which have non-territorial but locally knowledgeable floaters living amongst territorial families (Smith 1988). Under this classification scheme, the Coyote reported in this paper would be categorized as a "floater". Floaters (and other transients) presumably claim vacated territories following the death of resident territory holders.

In addition to the dramatic changes in movement patterns post-2004, the Coyote's behavior seemed to change during that period as well. First, we observed her six times sitting/hiding under decks and/or sheds (Figure 3) but never documented her using human structures for rest/denning the previous six years (Way et al. 2001). F. Harrington (personal communication) noted a young male Wolf (\#2489) in Minnesota that similarly localized following the abandonment of his natal territory after his father died. The Wolf appeared to be in a state of shock, yet was alive and eventually emigrated $160 \mathrm{~km}$ away. Perhaps when Wolves/Coyotes are forced to leave their territories through social expulsion, the animals sink into an apparent state of depression and hide from other canids (F. Harrington, personal communication). Second, while radio-tracking the Coyote as a territorial pack member (19982004), we regularly heard (and video-recorded) her group howling (i.e., at least twice a week). However, we heard her vocalize only three times during her nomadic phase(s) (i.e., early-2005 to early-2007): (1) on 24 April 2005 at $2124 \mathrm{~h}$ when she and one or two other Coyotes engaged in a high-pitched and wailing group howl; (2) on 12 May 2005 at $2128 \mathrm{~h}$, when she and a second Coyote called each other via lone howls (or contact calls); and (3) on 9 August 2005 at $2128 \mathrm{~h}$, when a short bark and brief howl were heard near her location; this sounded like a warning call (Lehner 1978). These vocalizations occurred when she was traveling with another Coyote and living in a small home range (and possible territory) for 11 months at the northeastern edge of her former territory. This behavioral shift (i.e., lack of howling) by this Coyote may have been an attempt to avoid resident Coyote packs, similar to the behavior exhibited by Wolves to avoid resident Wolf packs (Mech and Boitani 2003a, b). As a long-lived individual, her knowledge of the area likely helped her to navigate around resident core 


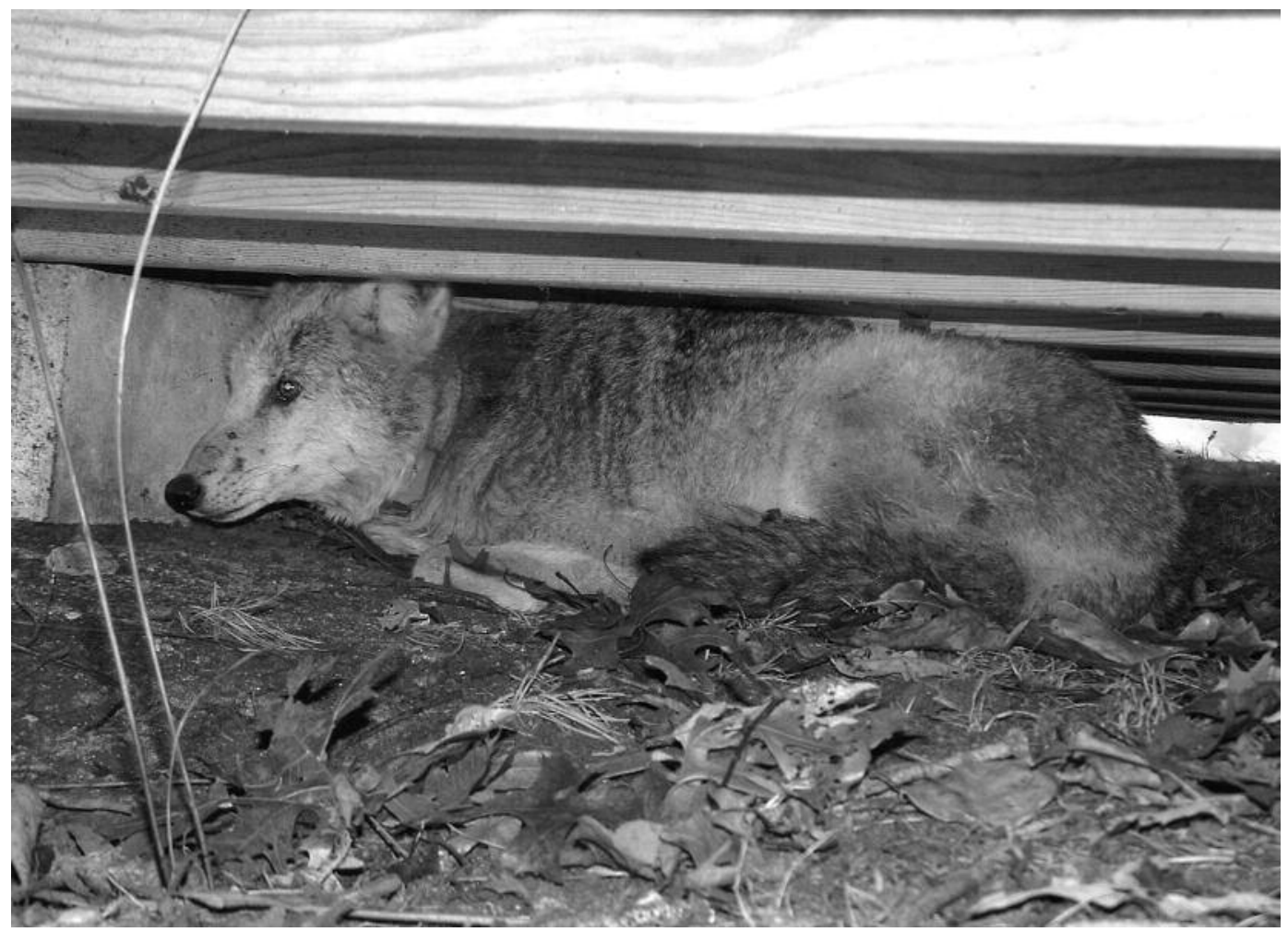

FIGURE 3. Coyote \#9804 sitting under a shed (January 2005) in a residential area at the southeastern portion of her former range, in West Yarmouth, Cape Cod, Massachusetts.

use areas, although the high number of unsuccessful finds for her in 2006 also suggests that she explored surrounding areas potentially inhabited by other (uncollared) packs. Third, Red Foxes were seen in close proximity to the Coyote $(<200 \mathrm{~m})$ much more frequently during her nomadic phase(s) than during her territorial phase (i.e., 1998 - 2004). Our data indicated that she lived at the periphery of resident Coyote packs' ranges, and in more clustered areas, likely a tactic to avoid encountering resident Coyotes (Figure 1). Larger canids are dominant over smaller ones, (e.g., Wolves over Coyotes and Coyotes over Foxes) (Major and Sherburne 1987; Harrison et al. 1989; Johnson et al. 1996) and therefore the observations of foxes in close proximity to the Coyote suggests that she may have been perceived as less of a threat by foxes during her nomadic phase, she may have been less aggressive to the foxes, and/or that both the Coyote and foxes were spending the majority of their time in areas of low use by resident Coyote packs.

We suggest that one possible mechanism for this dramatic range shift is that the Coyote, due to her advanced age (i.e., she was $\sim 10$ years-old in 2005), became post-reproductive and may have been unable to defend (or relinquished) her original (i.e., 1998-2004) territory. Sacks (2005) found that female Coyotes in California reproduced at eight and nine years old in that short-lived population (mean age of females was about three years old), while Dumond and Villard (2000) noted reproduction in $83 \%(n=6)$ of female Coyotes $>8$ years old in New Brunswick. Our study subject successfully reproduced until 10 years old even though she tested positive for heartworm and Lyme disease during her previous captures. Possibly the combined effects of these parasites and her advanced age caused her loss of vigor and subsequent abandonment (or loss) of her territory.

This study illustrates the importance of (1) longterm studies of individuals; (2) documenting the fate of old, possibly post-reproductive canids; and (3) providing an account of the behavior of a formerly territorial canid that lost its territory and became a floater. Researchers should not ignore the importance of monitoring individuals throughout their lives to gain a more accurate behavioral profile of the species.

\section{Acknowledgments}

This study would not have been possible without the help from Tara Way and the Way family, Eric Strauss and Boston College, Barnstable High School, 
and the Hyannis Animal Hospital (specifically, Larry Venezia). F. Harrington and an anonymous reviewer provided helpful comments.

Documents Cited (marked $*$ in text)

Way, J. G. 2007. Suburban howls: Tracking the eastern coyote in urban Massachusetts. Dog Ear Publishing, Indianapolis, Indiana. http://www.easterncoyoteresearch.com.

\section{Literature Cited}

Andelt, W. F. 1985. Behavioral ecology of coyotes in south Texas. Wildlife Monographs 49: 1-45.

Crabtree, R. L., and J. W. Sheldon. 1999. Coyotes and canid coexistence in Yellowstone. Pages 127-163 in Carnivores in ecosystems: the Yellowstone experience. Edited by T. W. Clark, A. P. Curlee, S. C. Minta, and P. M. Kareiva. Yale University Press, New Haven, Connecticut.

Dumond, M., and M.-A. Villard. 2000. Demography and body condition of coyotes (Canis latrans) in eastern New Brunswick. Canadian Journal of Zoology 78: 399-406.

Gese, E. M., and L. D. Mech. 1991. Dispersal of wolves (Canis lupus) in northeastern Minnesota, 1969-1989. Canadian Journal of Zoology 69: 2946-2955.

Gese, E. M., R. L. Ruff, and R. L. Crabtree. 1996. Social and nutritional factors influencing the dispersal of resident coyotes. Animal Behaviour 52: 1025-1043.

Harrison, D. J. 1992. Dispersal characteristics of juvenile coyotes in Maine. Journal of Wildlife Management 56: 128-138.

Harrison, D. J., J. A. Bissonette, and J. A. Sherburne. 1989. Spatial relationships between coyotes and red foxes in eastern Maine. Journal of Wildlife Management 53: 181185.

Johnson, W. E., T. K. Fuller, and W. L. Franklin. 1996. Sympatry in canids: a review and assessment. Pages 189 218 in Carnivore behavior, ecology, and evolution. Edited by J. L. Gittleman. Comstock Publishing Associates, Cornell University Press, Ithaca, New York.

Lehner, P. N. 1978. Coyote vocalizations: A lexicon and comparisons with other canids. Animal Behaviour 26: 712722.

Major, J. T., and J. A. Sherburne. 1987. Interspecific relationships of coyotes, red foxes, and bobcats in western Maine. Journal of Wildlife Management 51: 606-616.

Mech, L. D., L. G. Adams, T. J. Meier, J. W. Burch, and B. W. Dale. 1998. The wolves of Denali. University of Minnesota Press, Minneapolis, Minnesota.

Mech, L. D., and L. Boitani. 2003a. Wolf social ecology. Pages 1-34 in Wolves: behavior, ecology, and conservation. Edited by L. D. Mech and L. Boitani. University of Chicago Press, Chicago, Illinois, USA. 448 pages.
Mech, L. D., and L. Boitani. Editors. 2003b. Wolves: behavior, ecology, and conservation. University of Chicago Press, Chicago, Illinois.

Parker, G. R. 1995. Eastern coyote: the story of its success. Nimbus Publishing, Halifax, Nova Scotia, Canada.

Patterson, B. R., and F. Messier. 2001. Social organization and space use of coyotes in eastern Canada relative to prey distribution and abundance. Journal of Mammalogy 82: 463-477.

Person, D. K., and D. H. Hirth. 1991. Home range and habitat use of coyotes in a farm region of Vermont. Journal of Wildlife Management 55: 433-441.

Rodgers, A. R, A. Carr, H. L. Beyer, L. Smith, and J. G. Kie. 2007. HRT: Home Range Tools for ArcGIS. Version 1.1. Ontario Ministry of Natural Resources, Centre for Northern Forest Ecosystem Research, Thunder Bay, Ontario, Canada .

Sacks, B. N. 2005. Reproduction and body condition of California coyotes (Canis latrans). Journal of Mammalogy 86: 1036-1041.

Smith, S. M. 1988. Flock switching in chickadees: Why be a winter floater? The American Naturalist 123: 81-98.

Way, J. G. 2003. Descriptions and possible reasons for an abnormally large group size of adult eastern coyotes observed during summer. Northeastern Naturalist 10: 335342.

Way, J. G. 2007. Movements of transient Coyotes (Canis latrans var.) in urbanized eastern Massachusetts. Canadian Field-Naturalist 121: 364-369.

Way, J. G., P. J. Auger, I. M. Ortega, and E. G. Strauss. 2001. Eastern coyote denning behavior in an anthropogenic environment. Northeast Wildlife 56: 18-30.

Way, J. G., I. M. Ortega, and P. J. Auger. 2002a. Eastern coyote home range, territoriality and sociality on urbanized Cape Cod, Massachusetts. Northeast Wildlife 57: 118.

Way, J. G., I. M. Ortega, P. J. Auger, and E. G. Strauss. 2002b. Box-trapping eastern coyotes in southeastern Massachusetts. Wildlife Society Bulletin 30: 695-702.

Way, J. G., I. M. Ortega, and E. G. Strauss. 2004. Movement and activity patterns of eastern coyotes in a coastal, suburban environment. Northeastern Naturalist 11: 237254.

Way, J. G., and R. L. Proietto. 2005. Record size female Coyote, Canis latrans. Canadian Field-Naturalist 119: 139140.

Way, J. G., and E. G. Strauss. 2004. Old-aged coyote in an urbanised landscape. Canid News 7.2: 1-3. URL: http:// www.canids.org/canidnews/7/Old_aged_coyote.pdf.

Received 28 September 2008

Accepted 27 May 2009

\section{ADDENDA: \\ While this paper was in press, the eastern Coyotes have been demonstrated to be hybrids from cross- es between the Western Coyote, Canis latrans, and the Eastern Wolf, Canis lycaon, and should now be referred to as "Coywolf" Canis latrans $\times$ lycaon. \\ In press: Genetic characterization of eastern "coyotes" in eastern Massachusetts" by Jonathan G. Way, Linda Ruttledge, Tyler Wheeldon, and Bradley N. White. Northeastern Naturalist 17 (2010).}

